\title{
Value of split-bolus multidetector-row CT technique in the quantitative assessment of pancreatic enhancement
}

\section{Pankreatik tutulumun kantitatif değerlendirilmesinde bölünmüş-bolus multidetektör-dizi BT tekniğinin değeri}

\author{
Michele SCIALPI ${ }^{1}$, Valeria RONDONI ${ }^{1}$, Nicola RECCHIA ${ }^{1}$, Francesco BARBERINI ${ }^{2}$, Paolo BACCARI ${ }^{2}$, \\ Maria Antonietta MAZZEI ${ }^{3}$, Lucia MANGANARO ${ }^{4}$, Luca RONCATI ${ }^{5}$, Teresa PUSIOL ${ }^{6}$, Barbara PALUMBO7
}

\begin{abstract}
The aim of this study is to quantitatively assess radiation com$m a$, and pancreatic enhancement by split-bolus intravenous injection of contrast material using 64-slice CT. Single-pass splitbolus MDCT of the chest and abdomen was performed in 37 patients (female: 18 , male: 9; mean age, $66.1 \pm 14.2$ years; range 17-80 years) without pancreatic disease. Regions of interest in the pancreatic head, body and tail were drawn, and mean attenuation values for pancreatic parenchymal phase (PPP) of the standard MDCT protocol and split-bolus were calculated. $P<0.05$ was considered statistically significant. Mean effective dose by split-bolus was measured. In all MDCT examinations split-bolus protocol allowed acquisition of optimal images. Mean pancreatic enhancement was higher by split-bolus with respect to PPP of

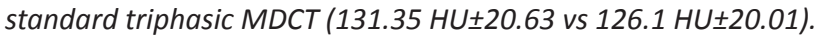
Reduction of dose using MDCT split-bolus was approximately $17 \%$. In conclusion MDCT split-bolus protocol provides an optimal pancreatic enhancement, significantly greater than the enhancement of standard MDCT on PPP which confers an advantage for the detection and staging of pancreatic tumors.
\end{abstract}

Keywords: Pancreas, multidetector-row computed tomography, radiation dose, oncology öz

Bu çalışmanın amacı, bölünmüş-bolus intravenöz kontrast madde kullanılarak yapılan 64 kesitli BT ile pankreatik artışı ve radyasyon dozunu kantitatif olarak değerlendirmektir. Pankreatik bir hastalığı olmayan 37 hastaya (kadın: 18, erkek: 9, ortalama yaş: 66,1 14,2 yaş, aralık 17-80 yaş) göğüs ve abdomen tek geçiş bölünmüş-bolus MDBT uygulandı. Pankreas başı, gövdesi ve kuyruğundaki ilgili bölgeler değerlendirildi ve standart MDBT protokolünün pankreatik parankimal faz (PPF) için ortalama zayıflama değerleri ve bölünmüş-bolus dozları ölçüldü. $P<0.05$ değeri istatistiksel olarak anlamlı kabul edildi. Bölünmüş-bolus uygulamasının ortalama efektif dozu ölçüldü. Tüm MDBT incelemelerinde bölünmüş-bolus protokolü kaliteli görüntülere izin verdi. Ortalama panreatik artış PPF için bölünmüş-bolus uygulamasında standart trifazik MDBT e göre daha yüksekti (131,35 HU士20,63 vs 126.1 HU士20.01). bölünmüş bolus dozlu MDBT 'de dozda azalma yaklaşık olarak \%17 idi. Sonuç olarak, bölünmüş-bolus protokollü MDBT optimal pankreatik artış sağlar, pankreatik parankimal faz için özellikle standart MDBT değerlendirmesine göre önemli ölçüde üstünlük sağlar ve pankreas tümörlerinin belirlenmesi ve evrelemesi için avantajlıdır.

Anahtar kelimeler: Pankreas, multidetektör-dizi bilgisayarlı tomografi, radyasyon dozu, onkoloji

\section{INTRODUCTION}

Currently radiological techniques are the procedures of choice in the identification of malformative, inf- lammatory and neoplastic diseases ${ }^{1-3}$; histopathological analyses confirm the radiological diagnosis ${ }^{4,5}$.

Multidetector-row Computed Tomography (MDCT) is

Received: 10.04 .2017

Accepted: 12.06 .2017

${ }^{1}$ Department of Surgical and Biomedical Sciences, Division of Radiology and Nuclear Medicine, Perugia University, S.Maria della Misericordia Hospital, Perugia, Italy

${ }^{2}$ Department of Surgical and Biomedical Sciences, S.Maria della Misericordia Hospital, Perugia, Italy

${ }^{3}$ Department of Radiology, University Hospital of Siena, Siena, Italy

${ }^{4}$ Department of Radiological, Oncological and Pathological Sciences, Sapienza University of Rome, Rome, Italy

${ }^{5}$ Department of Diagnostic and Clinical Medicine and of Public Health, Section of Pathology University of Modena and Reggio Emilia, Modena, Italy

${ }^{6}$ Institute of Anatomic Pathology, Santa Maria del Carmine Hospital, Rovereto, Italy

${ }^{7}$ Division of Nuclear Medicine, Department of Surgical and Biomedical Sciences, S.Maria della Misericordia Hospital, Perugia, Italy.

Yazışma adresi: Michele Scialpi, Department of Surgical and Biomedical Sciences, Division of Radiology and Nuclear Medicine, Perugia University, S.Maria della Misericordia Hospital, S. Andrea delle Fratte, 06156 Perugia, Italy

e-mail: michelescialpi1@gmail.com; michelescialpi@libero.it 
the most widely used method for the evaluation of pancreatic and non-pancreatic neoplastic diseases ${ }^{6-8}$. In this setting the knowledge of magnitude and consistency of the normal pancreatic enhancement and of optimal contrast differences between pancreas tumor and pancreas parenchyma is essential to ensure detection of lesions and accurate evaluation of peripancreatic vessels or lymph nodes ${ }^{9,10}$.

In the literature a multitude of CT protocols for the assessment of pancreatic enhancement and staging of pancreatic tumors has been reported. Standard CT protocols involve bi- or triphasic techniques with different results; one of the most relevant limitation of multiphasic CT technique is the patient's exposure to increased radiation doses ${ }^{11-24}$.

Recently, instead of standard pancreatic multiphase or pancreatic CT, split-bolus MDCT (SB-MDCT) technique for detection, staging and follow-up of pancreatic tumors has been proposed ${ }^{25}$. SB-MDCT, combining arterial phase (AP) and portal venous phase (PVP), allows a better tumor conspicuity reducing radiation dose.
At our institution, we implemented the SB-MDCT protocol for oncologic patients that combines AP and PVP in a single-pass enabling, in addition to images of diagnostic quality, a relevant reduction in radiation exposure and in the number of images to be read and stored ${ }^{26}$.

Our aim was to quantitatively assess pancreatic enhancement by split-bolus intravenous injection of contrast material using 64-section CT scanner, comparing the results with those obtained during late arterial or pancreatic parenchymal phase (PPP) of the standard multiphase MDCT.

\section{MATERIAL and METHODS}

\section{Patients}

For this retrospective study the institutional review board approval was obtained. We retrospectively reviewed follow-up thoracic, and abdominal SB 64-slice CTs (Philips Healthcare, Best, The Netherlands) of 37 patients (female: 18 , male: 9; mean age, 66.1 \pm 14.2 years; range $17-80$ years) with normal pancreas performed at our institution between February 2012

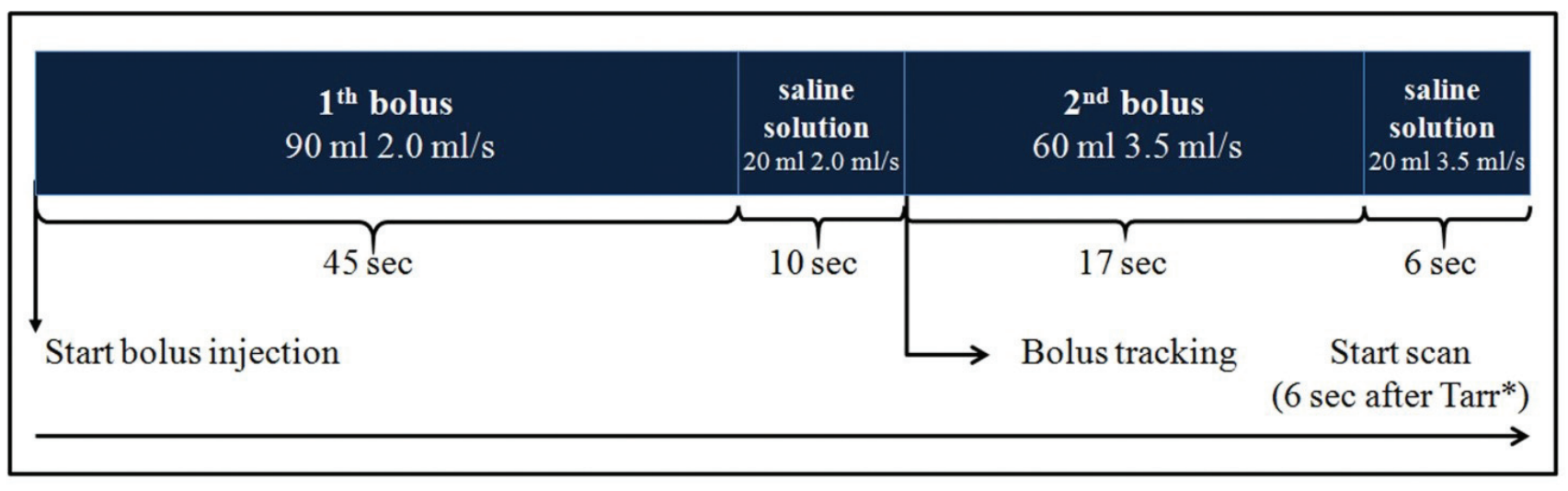

\section{* Contrast arrival time}

Figure 1. Schematic view of split-bolus 64-detector row CT scanning of the chest and abdomen in a $75 \mathrm{Kg}$ patient. First bolus [at the start of bolus injection (or time zero)]: $90 \mathrm{~mL}$ of contrast medium at $2.0 \mathrm{~mL} / \mathrm{sec}$, followed by $20 \mathrm{~mL}$ of saline solution at same flow rate, is injected to obtain adequate abdominal parenchymal and venous system enhancement; second bolus: $60 \mathrm{~mL}$ of contrast medium at 3.50 $\mathrm{mL} / \mathrm{s}$ followed by $20 \mathrm{~mL}$ of saline solution at the same flow rate to obtain hepatic arterial phase. We used bolus tracking set (raising the threshold value at $500 \mathrm{HU}$ ) with a circular region-of- interest (ROI) placed in the descending aorta. Approximately at the end of the second bolus injection of contrast medium, the scan started cranio-caudally after a delay of at least 6 sec from the arrival of the contrast medium in the aorta. Using the scout film, a scan range from the pulmonary apex to the pubic symphysis was determined. A single acquisition from the pulmonary apex to the pubic symphysis was performed, resulting in a simultaneous contrast enhancement of the arterial and venous system. 
and July 2014. These patients had undergone triphasic MDCT scanning for primary non-malignant pancreatic tumors between January 2011 and April 2013. No patient had history of pancreatic or liver disease or marked atrophy of the pancreatic parenchyma.

SB-MDCT protocol provided unenhanced scans of the upper abdomen and acquisition of the chestabdomen-pelvis in a single-pass after intravenous injection of contrast material (lopamidolo, lopamiro ${ }^{\circledR}$ $370 \mathrm{mgl} / \mathrm{mL}$; Bracco, Milano, Italy and lopromide, Ultravist ${ }^{\circledR} 370 \mathrm{mgl} / \mathrm{mL}$ Schering AG, Berlin, Germany), splitted into two boluses (Figure 1) by a power injector (Stelland CT; Medrad, Indianola, Pennsylvania).

In the SB-MDCT protocol, by applying simultaneous injections of two contrast material boli, provided a late arterial (or PPP) and a PVP, in a single-pass.

Volume of the contrast material was calculated as 2 $\mathrm{mL} / \mathrm{Kg}$, with a maximum dose of $150 \mathrm{~mL}$. A schematic representation of SB-MDC single pass in a $75 \mathrm{Kg}$ patient is shown in Figure 1.

Flow rate of the contrast material, duration of injection and injection times were established according to the literature data ${ }^{24,26-28}$, and broad clinical experience. Hepatic enhancement during PVP occured about 80-85 seconds after the start of intravenous injection of a bolus of contrast material and the PPP occured about 35 seconds after the start of intravenous injec- tion of a bolus of contrast material.

Thus, with the first dose of $90 \mathrm{~mL}$ of contrast material, $20 \mathrm{~mL}$ of saline were delivered at a flow rate of 2 $\mathrm{mL} / \mathrm{sec}$ within 55 seconds; the second dose of $60 \mathrm{~mL}$ of contrast material and $20 \mathrm{~mL}$ of saline was subsequently injected, and scanning (from the pulmonary apex) was performed 30 seconds after the second bolus for PPP or 85 seconds after the first bolus for PVP.

We used manual bolus-tracking technique for the start of the scan. Threshold value at 500 Hounsfield Units (HU) was raised and a circular region of interest (ROI) in the descending aorta was determined. The scan was started manually 6 seconds after the arrival of the second bolus of contrast material in the aorta, and from the pulmonary apex to the pubic symphysis was scanned.

In a single-pass a synchronous optimal hepatic enhancement during PVP and PPP was obtained.

For SB-MDCT technique, the following acquisition parameters were set: slice thickness $2.5 \mathrm{~mm}$; gantry rotation speed 0.75 seconds; pitch 0.935:1; reconstruction index 1.25; tube voltage $120 \mathrm{kVp}$; for the tube current was used the automatic milliampere setting, based on patient's weight.

MDCT examinations were completed with sagit-

Table 1. Mean attenuation values (in HU) in 37 patients with normal pancreatic parenchyma at split-bolus and on pancreatic parenchymal phase of standard MDCT in our experience and in literature.

\begin{tabular}{|c|c|c|c|c|c|c|c|}
\hline & \multirow{2}{*}{$\begin{array}{c}\text { Mean } \\
\text { attenuation } \\
\text { values on } \\
\text { PPP* }\end{array}$} & \multicolumn{3}{|c|}{$\begin{array}{c}\text { Mean attenuation values } \\
\text { on PPP }\end{array}$} & \multicolumn{3}{|c|}{$\begin{array}{l}\text { Mean attenuation values on } \\
\text { split-bolus }\end{array}$} \\
\hline & & $\begin{array}{l}\text { Maximum } \\
\text { mean value }\end{array}$ & $\begin{array}{l}\text { Minimum } \\
\text { mean value }\end{array}$ & $\begin{array}{l}\text { Mean } \\
\text { value }\end{array}$ & $\begin{array}{l}\text { Maximum } \\
\text { mean value }\end{array}$ & $\begin{array}{l}\text { Minimum } \\
\text { mean value }\end{array}$ & $\begin{array}{l}\text { Mean } \\
\text { value }\end{array}$ \\
\hline Pancreas & 122 & 165.80 & 65.7 & 126 & 165.80 & 65.7 & 126 \\
\hline Celiac axis & 228 & 474.81 & 205.3 & 324.3 & 474.81 & 205.3 & 324.3 \\
\hline SMA & 245 & 420.10 & 179 & 314.39 & 420.10 & 179 & 314.39 \\
\hline SMV & 171 & 269.5 & 119.8 & 180.79 & 269.5 & 119.8 & 180.79 \\
\hline Portal vein & 180 & 240.22 & 115.6 & 190.48 & 240.22 & 115.6 & 190.48 \\
\hline
\end{tabular}

*Data reported by Mc Nulty et al. ${ }^{9}$; SMA: superior mesenteric artery; SMV: superior mesenteric vein. 
tal, coronal and curved multiplanar reconstructions (MPR).

\section{Analyses of Images}

All CT images were transferred from local digital media to a viewing station (Advantage Workstation 4.2; Magicview Philips, Nederlands) and independently reviewed by two radiologists (M.S., A.D.A.) with at least 25 , and 15 years of experience in interpreting body CT images, respectively.

Image quality was rated on the following 5-point scale:

1. Excellent (excellent delineation of the pancreas and of the surrounding structures);

2. Good (good pancreas delineation, low background noise);

3. Adequate (adequate delineation of the pancreas and of surrounding structures, mild background noise);

4. Poor (poor definition of pancreas, low attenuation and difficult delineation of the structures, increased image noise, diagnostic confidence reduced); poor delineation of the pancreas and peripancreatic structures, considerable background noise);

5. Very poor, not diagnostic.

The two radiologists also reported all factors influencing quality of images (obesity, metallic and motion artifacts, contrast timing and contrast material flowrelated).

The attenuation values of the pancreas in $\mathrm{HU}$, were measured positioning three circular ROls of equal size, in the most homogeneous regions of the head, the body and the tail of the pancreas, respectively, and then the mean attenuation in $\mathrm{HU}$ was calculated.

Mean attenuation values of the SB-MDCT were compared with the values of the PPP obtained in our experience and reported in the literature ${ }^{9,25}$.

The statistical significance of the comparison was as- sessed by Student's t test. P value $<0.05$ was considered statistically significant.

\section{Dose Radiation Analysis}

The dosimetric evaluation was performed analyzing the MDCT examinations with SB protocol in the patients enrolled in the study. Radiation dose measurement was based on volume CT dose index (CTDIvol) and dose-length-product (DLP). The effective dose (ED; Sievert, Sv) was calculated using the following equation:

$E D=k \times D L P \quad k=0.015$ (conversion coefficient) ${ }^{30}$.

\section{RESULTS}

SB- MDCT technique provided imaging of high quality in all cases.

Mean attenuation values in $\mathrm{HU}$, concentration and volume of contrast material in 37 patients with normal pancreatic parenchyma who underwent SBMDCT and those obtained on PPP in our experience and in the literature are shown in Table 1.

The mean enhancement value of normal pancreatic parenchyma (mean values in the head, body, and tail) by SB-MDCT was $131.35 \mathrm{HU} \pm 20.63$ (ranged from 84.15 to $187.3 \mathrm{HU}$ ), and it was higher than that of the mean enhancement value on PPP of standard multiphase MDCT technique reported in the literature (122 HU) and in our experience (126.1 HU \pm 20.01 , ranged from 65.7 to $165.80 \mathrm{HU})$. Difference between the mean attenuation values of SB-MDCT and PPP of standard MDCT technique in our experience was not statistically significant $(P=0.27)$. These values were higher comparing with those reported on PPP in the literature (average $122 \mathrm{HU})^{9}$.

Maximal enhancement of the celiac axis observed on SB-MDCT and on PPP of standard triphasic MDCT in our experience (456.9 HU vs $474.81 \mathrm{HU}$ ) was substantially similar, and statistically significant difference was not detected between the mean attenuation 
values of celiac axis at SB-MDCT and those of the standard multiphase protocol at PPP (310.6 HU vs $324.3 \mathrm{HU}$ respectively; $\mathrm{P}=0.34$ ).

Maximal enhancement of superior mesenteric artery observed during SB-MDCT and PPP of standard MDCT was $420 \mathrm{HU}$ vs $420.1 \mathrm{HU}$ respectively; any statistically significant difference was not observed between the mean attenuation values at SB-MDCT and those of the standard multiphase protocol at PPP $(298.77 \mathrm{HU}$ vs 314.39 HU respectively; $\mathrm{P}=0.27$ ).

Maximal enhancement of the superior mesenteric vein and portal vein was observed during the SBMDCT. A statistically significant difference was not observed between the mean attenuation values of superior mesenteric vein at SB-MDCT and those of the standard multiphase protocol at PVP $(195.85 \mathrm{HU}$ vs $180.79 \mathrm{HU}$ respectively; $\mathrm{P}=0.06$ ).

The attenuation values of the main portal vein at SB-MDCT were significantly higher than those of the standard multiphase protocol at PVP $(215.03 \mathrm{HU}$ vs $190.48 \mathrm{HU}$, respectively; $\mathrm{P}=0.001)$.

A representative case of pancreas with normal contrast enhancement at SB-MDCT is shown in Figure 2.

In our 37 patients, whole-body SB-MDCT in a singlepass provided a radiation dose in $\mathrm{mSv}$ ranged from 12.14 to $27.01 \mathrm{mSv}$ (average $19.3 \pm 6.3 \mathrm{mSv}$ ) with a reduction of approximately $17 \%$ with respect to stan-
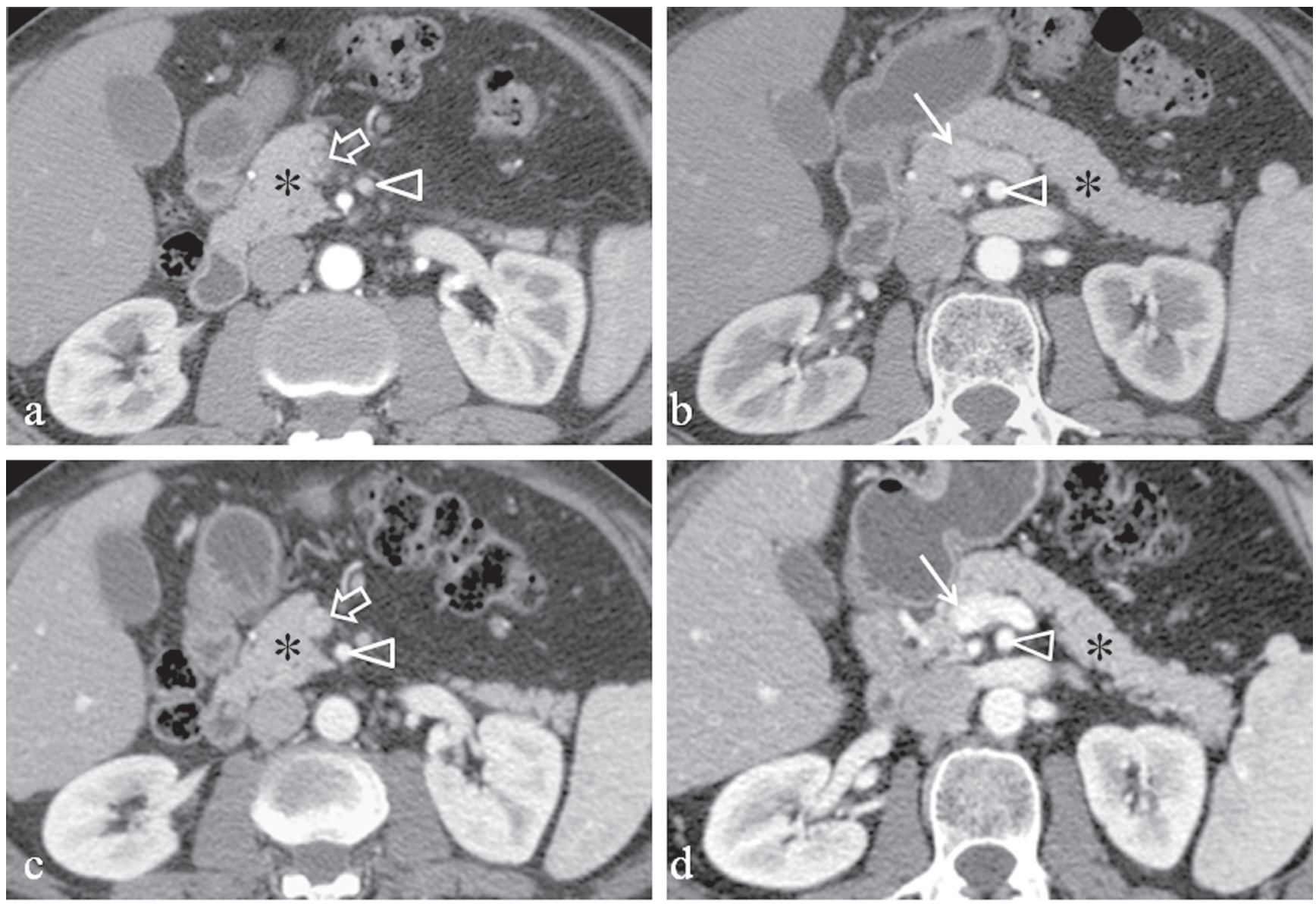

Figure 2. 60-year-old man with normal pancreas. Pancreatic parenchymal phase during triphasic $(a, b)$ MDCT and combined arterial-venous phase of the split-bolus (c,d) MDCT technique. Pancreatic parenchymal phase $(a, b)$ shows pancreatic parenchyma $(*)$ which is $114.6 \mathrm{HU}$ compared with $141.2 \mathrm{HU}$ of combined arterial-venous phase of the split-bolus (c,d). On combined arterial and venous phase of split bolus (c,d) MDCT, there is also greater enhancement of the superior mesenteric artery (arrow head in c,d) and mesenteric vein (arrow in c) and portal vein (thin arrow in d). 
dard triphasic MDCT in our experience. A potentially dose reduction can be obtained when compared with an unenhanced acquisition, and SB of the upper abdomen. Our results were lower than those reported in the literature ${ }^{25}$.

\section{DISCUSSION}

MCDT is the procedure of choice in the identification of pancreatic malignancy ${ }^{6}$ and other unusual tumors ${ }^{7,8}$. CT, in particular, is the method of choice in the assessment of normal pancreatic parenchyma and in the detection and staging of pancreatic adenocarcinoma $a^{9,12,20}$. The majority of standard CT protocols ${ }^{9,11,12,31-34}$, entails an unenhanced acquisition followed by pancreatic parenchymal phase (PPP), portal venous phase (PVP) and delayed phase.

This combination of contrast phases, although performed with different CT scanners, flow rates and volumes of contrast material, provides perfect conspicuity of pancreatic tumor, its proximity to vessels and detection of metastases. PPP during the standard bior triphasic $\mathrm{CT}$, is the most sensitive phase for the evaluation of pancreatic parenchyma ${ }^{9,20}$. An average volume of $135 \mathrm{~mL}$ of contrast material delivered at a flow rate of $4 \mathrm{~mL} / \mathrm{sec}$, provides a pancreatic enhancement ranging from $82.2 \mathrm{HU}$ to $122 \mathrm{HU}$ (average $105.7 \mathrm{HU})^{9}$.

Nevertheless, multiphase CT also exposes the patient to very high radiation doses.

Recently, to reduce the radiation exposure and to maintain diagnostic value of $\mathrm{CT}$ and its image quality, split-bolus (SB) contrast injection with spectral MDCT imaging of the normal pancreas and pancreatic adenocarcinoma has been proposed ${ }^{25}$.

As radiologists we need to reduce the radiation exposure, due to its known risks, without deterioration of the image quality and, most importantly, maintaining diagnostic efficacy of the CT scan. Among CT protocols for pancreas evaluation, the aim is to obtain an optimal pancreatic enhancement to identify normal pancreatic parenchyma and to maximize the attenuation difference between the tumor and the surrounding pancreatic parenchyma.

In addition, assessment of peripancreatic vessels, lymph nodes and detection and characterization of focal liver lesion are needed.

Our aim is to evaluate the feasibility of SB 64multidetector row CT compared to PPP of the standard MDCT scan protocol in the evaluation of the enhancement of the normal pancreatic parenchyma.

In the study of Brook et al. ${ }^{25}$, using CT unit with spectral imaging, SB spectral CT was combined with pancreatic and portal venous phases in a single scan through two contrast material injections separated by a short pause: 70 seconds before CT, $100 \mathrm{~mL}$ of contrast materials were injected for the PVP, followed by a second injection of $40 \mathrm{~mL}$ of contrast material approximately 35 seconds later, to boost the pancreatic phase. Using the bolus-tracking technique scanning started 15 seconds after aorta attenuation reached $280 \mathrm{HU}$. Mean values of enhancement of normal pancreatic parenchyma for SB and standard protocol in PPP were 212.2 HU士64.7 vs $105.1 \mathrm{HU} \pm 29.3$ respectively and the mean effective dose by SB was 20 $\mathrm{mSv} v^{25}$.

Our results, with respect to the normal pancreatic enhancement, differ from those of Brook because our study included patients of different ages and weights. Besides, we did not use CT unit with spectral imaging and, finally, injections of two contrast materials were not separated by a short pause and flow rate and volume of contrast materials were different.

These results have encouraged the use of SB-MDCT technique in the evaluation of the pancreas because this improvement in enhancement can enable a greater conspicuity and visualization of the pancreatic neoplasm and other pancreatic abnormalities. SB-MDCT also provides an accurate evaluation of the peripancreatic arterial and venous vessels and lymph nodes, that is essential to stage pancreatic cancer. In 
addition synchronous phases (arterial and parenchymal hepatic enhancement during PVP) provide an optimal evaluation of both pancreas and liver (ie detection of hypervascular and hypovascular metastases). A further advantage of the SB-MDCT protocol is reduction of the effective dose of radiation compared to bi- or triphasic MDCT technique.

A potential reduction of radiation dose down to $60 \%$ should be obtained if the SB-MDCT protocol was used in the study of the upper abdomen. This is important for example in the follow-up of the patients with necrotizing pancreatitis, in whom it is necessary to rescan them 7-10 days later, to evaluate size, extension and characteristics of the postnecrotic fluid collections.

Study limitation: our study included a small number of patients with different ages and body weights without pancreatic abnormalities, who had undergone whole body CT in the follow-up for malignant tumor.

In conclusion, these preliminary results demonstrated the effectiveness of SB 64-section MDCT scanner in the evaluation of the pancreas. The advantages of SB-MDCT protocol in the study of the pancreas are its ability to provide an optimal enhancement of the normal pancreatic parenchyma that allows detection of the tumor, in addition to the possibility to minimize radiation dose and number of images and data to be stored.

\section{REFERENCES}

1. Manganaro L, Scialpi M, Piscioli F, et al. MRI prenatal diagnosis of genitourinary abnormalities in a case of inconclusive ultrasonography. J Obstet Gynaecol 2016;36(6):762-763. https://doi.org/10.3109/01443615.2016.1157154

2. Manganaro L, Vinci V, Giancotti A, et al. Bi-parametric magnetic resonance imaging applied to obstetrics. J Obstet Gynaecol 2017;17:1-3. https://doi.org/10.1080/01443615.2017.1281237

3. Pusiol T, Scialpi M. Role of computed tomography in the preoperative diagnosis of giant benign solitary fibrous tumor pleura. Lung India 2013;30(1):82-5. https://doi.org/10.4103/0970-2113.106128

4. Pusiol T, Zorzi MG, Morichetti D, et al. Uselessness of percutaneous core needle renal biopsy in the management of small renal masses. Urol Int 2011;87(1):125-6.

https://doi.org/10.1159/000328195
5. Pusiol T, Zorzi MG, Morichetti D, et al. Uselessness of radiological differentiation of oncocytoma and renal cell carcinoma in management of small renal masses. World $\mathrm{J}$ Urol 2013;31(4):1013-4.

https://doi.org/10.1007/s00345-011-0693-0

6. Scialpi $M$, Cagini L, Pierotti L, et al. Detection of small (>2 $\mathrm{cm})$ pancreatic adenocarcinoma and surrounding parenchyma: correlations between enhancement patterns at triphasic MDCT and histologic features. BMC Gastroenterol 2014;14:16.

https://doi.org/10.1186/1471-230X-14-16

7. Scialpi M, Schiavone R, Basilicata A, et al. Radiation dose reduction thanks to split-bolus multi-detector computer tomography (MDCT) in children with non-thoracic neuroblastoma. Pediatr Blood Cancer 2015;62(10):1865-6.

https://doi.org/10.1002/pbc.25567

8. Scialpi M, Pierotti L, Gravante S, et al. Split-bolus versus triphasic multidetector-row computed tomography technique in the diagnosis of hepatic focal nodular hyperplasia: a case report. J Med Case Rep 2014;8:425. https://doi.org/10.1186/1752-1947-8-425

9. McNulty NJ, Francis IR, Platt JF, et al. Multi-detector row helical CT of the pancreas: effect of contrast-enhanced multiphasic imaging on enhancement of the pancreas, peripancreatic vasculature, and pancreatic adenocarcinoma. Radiology 2001;220:97-102.

https://doi.org/10.1148/radiology.220.1.r01jl1897

10. Brennan DD, Zamboni GA, Raptopoulos VD, Kruskal JB. Comprehensive preoperative assessment of pancreatic adenocarcinoma with 64-section volumetric CT. Radiographics 2007;27(6):1653-66. https://doi.org/10.1148/rg.276075034

11. Hollett MD, Jorgensen MJ, Jeffrey RB Jr. Quantitative evaluation of pancreatic enhancement during dual-phase helical CT. Radiology 1995;195:359-361.

https://doi.org/10.1148/radiology.195.2.7724753

12. Graf O, Boland GW, Warshaw AL, et al. Arterial versus portal venous helical CT for revealing pancreatic adenocarcinoma: conspicuity of tumor and critical vascular anatomy. AJR Am J Roentgenol 1997;169:119-123.

https://doi.org/10.2214/ajr.169.1.9207510

13. Lu DSK, Vedantham S, Krasny RM, et al. Two-phase helical CT for pancreatic tumors: pancreatic versus hepatic phase enhancement of tumor, pancreas and vascular structures. Radiology 1996;199:697-701. https://doi.org/10.1148/radiology.199.3.8637990

14. Choi BI, Chung MJ, Han JK, et al. Detection of pancreatic adenocarcinoma: relative value of arterial and late phases of spiral CT. Abdom Imaging 1997;22:199-203. https://doi.org/10.1007/s002619900172

15. Boland GW, O'Malley ME, Saez M, et al. Pancreatic-phase versus portal vein-phase helical CT of the pancreas: optimal temporal window for evaluation of pancreatic adenocarcinoma. AJR Am J Roentgenol 1999;172:605-608. https://doi.org/10.2214/ajr.172.3.10063844

16. Lu DSK, Reber HA, Krasny RM, et al. Local staging of pancreatic cancer: criteria for unresectability of major vessels as revealed by pancreatic-phase, thin-section helical CT. AJR Am J Roentgenol 1997;168:1439-1443. https://doi.org/10.2214/ajr.168.6.9168704

17. Keogan MT, McDermott VG, Paulson EK, et al. Pancreatic malignancy: effect of dual-phase helical CT in tumor detection and vascular opacification. Radiology 1997;205:513-518. https://doi.org/10.1148/radiology.205.2.9356637 
18. Raptopoulos V, Steer ML, Sheiman RG, et al. The use of helical CT and CT angiography to predict vascular involvement from pancreatic cancer: correlation with findings at surgery. AJR Am J Roentgenol 1997;168:971-977. https://doi.org/10.2214/ajr.168.4.9124153

19. Tabuchi T, Itoh K, Ohshio $\mathrm{G}$, et al. Tumor staging of pancreatic adenocarcinoma using early and late-phase helical CT. AJR Am J Roentgenol 1999;173:375-380. https://doi.org/10.2214/ajr.173.2.10430140

20. Fletcher JG, Wiersema MJ, Farrell MA, et al. Pancreatic malignancy: value of arterial, pancreatic, and hepatic phase imaging with multi-detector row CT. Radiology 2003;229:81-90. https://doi.org/10.1148/radiol.2291020582

21. Scaglione M, Pinto A, Romano S, et al. Using multidetectorrow computed tomography to diagnose and stage pancreatic carcinoma: the problems and the possibilities. JOP 2005;6:1-5.

22. Yamada $\mathrm{Y}$, Mori H, Matsumoto $\mathrm{S}$, et al. Pancreatic adenocarcinoma versus chronic pancreatitis: differentiation with triple-phase helical CT. Abdom Imaging 2010;35:163-171. https://doi.org/10.1007/s00261-009-9579-7

23. Yoshikawa J, Matsui O, Kadoya M, et al. Delayed enhancement of fibrotic areas in hepatic masses: CT-pathologic correlation. J Comput Assist Tomogr 1992;16:206-211. https://doi.org/10.1097/00004728-199203000-00006

24. Ichikawa T, Erturk SM, Sou H, et al. MDCT of pancreatic adenocarcinoma: optimal imaging phases and multiplanar reformatted imaging. AJR Am J Roentgenol 2006;187:1513-1520. https://doi.org/10.2214/AJR.05.1031

25. Brook OR, Gourtsoyianni S, Brook A, et al. Split-bolus spectral Multidetector CT of the Pancreas: Assessment of Radiation Dose and Tumor Conspicuity. Radiology 2013;269:139-148. https://doi.org/10.1148/radiol.13121409

26. Scialpi M, Palumbo B, Pierotti L, et al. Detection and characterization of focal liver lesions by split-bolus multidetectorrow CT: diagnostic accuracy and radiation dose in oncologic patients. Anticancer Res 2014;34(8):4335-4344.

27. Bae KT. Intravenous Contrast Medium Administration and Scan Timing in CT: Considerations and Approaches. State-ofthe-Art. Radiology 2010;256:32-61. https://doi.org/10.1148/radiol.10090908

28. Erturk SM, Ichikawa $\mathrm{T}$, Sou $\mathrm{H}$, et al. Effect of duration of contrast material injection on peak enhancement times and values of the aorta, main portal vein, and liver at dynamic MDCT with the dose of contrast medium tailored to patient weight. Clin Radiol 2008;63(3):263-71. https://doi.org/10.1016/j.crad.2007.02.024

29. Heiken JP, Brink JA, McClennan BL, et al. Dynamic incremental CT: effect of volume and concentration of contrast material and patient weight on hepatic enhancement. Radiology 1995;195:353-7. https://doi.org/10.1148/radiology.195.2.7724752

30. Deak PD, Smal Y, Kalender WA. Multisection CT Protocols: Sex- and Age-specifi c Conversion Factors Used to Determine Effective Dose from Dose-Length Product. Radiology 2010;257(1):158-166. https://doi.org/10.1148/radiol.10100047

31. Yanaga Y, Awai K, Nakayama Y, et al. Pancreas: Patient Body Weight tailored Contrast Material Injection Protocol versus Fixed Dose Protocol at Dynamic CT. Radiology 2007;245:475482.

https://doi.org/10.1148/radiol.2452061749

32. Kondo H, Kanematsu M, Goshima S, et al. MDCT of the pancreas: optimizing scanning delay with a bolus-tracking technique for pancreatic, peripancreatic vascular, and hepatic contrast enhancement. AJR Am J Roentgenol 2007;188:751756.

https://doi.org/10.2214/AJR.06.0372

33. Goshima S, Kanematsu M, Kondo H, et al. Pancreas: optimal scan delay for contrast-enhanced multi-detector row CT. Radiology 2006;241:167-174. https://doi.org/10.1148/radiol.2411051338

34. Schueller G, Schima W, Schueller-Weidekamm C, et al. Multidetector CT of Pancreas: Effects of Contrast Material Flow Rate and Individualized Scan Delay on Enhancement of Pancreas and Tumor Contrast. Radiology 2006;241:441-448. https://doi.org/10.1148/radiol.2412051107 